\title{
Spectroscopy of Linear Interstellar Carbon Chain Isotopologues: Meeting Experimental Accuracy
}

\author{
Etim, E.E. ${ }^{1 *}{ }^{(1)}$, Mbakara, I.E. ${ }^{2}$, Inyang, E.J. ${ }^{3}$, Ushie, O.A. ${ }^{1}$, Lawal, U. ${ }^{1}$, Andrew, C. ${ }^{1}$ \\ ${ }^{1}$ Department of Chemical Sciences, Federal University Wukari, Nigeria \\ ${ }^{2}$ Department of Chemistry, University of Ibadan, Nigeria \\ ${ }^{3}$ Department of Pure and Industrial Chemistry, University of Nigeria, Nigeria \\ *Corresponding author's email: emmaetim@gmail.com
}

\begin{abstract}
The fact that isotopologues do not suffer from opacity problems allows them to be used as sensitive probes of the chemical and physical conditions of the interstellar medium. For every molecular species, accurate spectroscopic parameters remain the fundamental requirements for successful astronomical observation. The low natural abundances of the linear carbon chain isotopologues make their laboratory detection difficult as compared to their corresponding main carbon chains and theoretical methods which are not able to give very accurate predictions for the main carbon chains cannot do so for the isotopologues. This work reports accurate spectroscopic constants for linear carbon chain isotopologues using the correlation between the spectroscopic constant of the carbon chains and their corresponding isotopologues. The reported spectroscopic constants are with the experimental accuracy of few $\mathrm{KHz}$ for the systems with known experimental parameters and the same high accuracy is expected for those with no experimental parameters; thus, can guide successful detection of these species. The possibility that most of the ' $U$ ' lines associated with the known linear interstellar carbon chains belong to their isotopologues cannot be totally ruled out. With the availability of accurate rotational constants, some of the ' $\mathrm{U}$ ' lines could be assigned.
\end{abstract}

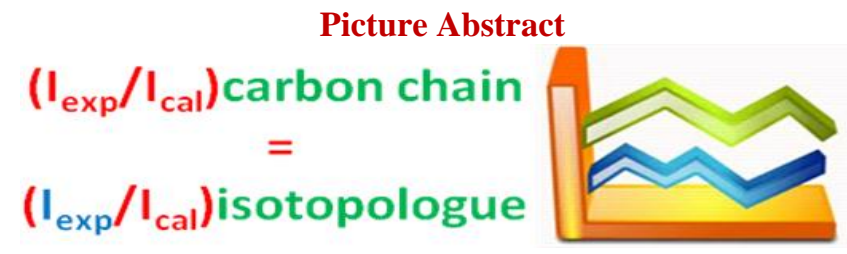

Original Research Article

Received: $17^{\text {th }}$ Aug., 2017.

Accepted: $4^{\text {th }}$ Oct., 2017.

Published: $23^{\text {rd }}$ Oct., 2017

Keywords:

Isotopologues;

'U'-lines;

Carbon chains;

Astrochemistry;

Spectroscopy.

\section{INTRODUCTION}

$\mathrm{T}$ The interaction initiated in the 19th century between spectroscopists and astronomers for the purpose of assigning the Fraunhofer lines in the solar spectrum to atomic transitions has remained fruitful, successful and ever fascinating. This interaction has led to the successful detection of over 200 different molecular species in the interstellar medium (ISM) and circumstellar envelopes ranging from the simple diatomics to the complex species (those with six atoms and above) including the buckyballs with each molecule telling the story of the chemistry and physics of the environment from where it was observed. Also, every known interstellar or circumstellar molecular species points to the presence and detectability of related species. The use of these molecular species as probes of the physical conditions in space has emerged as one of the major driving forces for the increased interest in the fields of astronomy, astrophysics and other related fields (Wlodarczak, 1995; Etim and Arunan, 2015).

Among the known interstellar and circumstellar molecules, the linear carbon chains of the form; $\mathrm{C}_{\mathrm{n}}, \mathrm{H}_{2} \mathrm{C}_{\mathrm{n}}, \mathrm{HC}_{\mathrm{n}} \mathrm{N}, \mathrm{HC}_{\mathrm{n}} \mathrm{O}$, $\mathrm{CH}_{3}(\mathrm{C} \equiv \mathrm{C})_{\mathrm{n}} \mathrm{H}, \mathrm{CH}_{3}(\mathrm{C} \equiv \mathrm{C})_{\mathrm{n}} \mathrm{CN}$, and $\mathrm{C}_{\mathrm{n}} \mathrm{X} \quad(\mathrm{X}=\mathrm{N}, \mathrm{O}, \mathrm{Si}, \mathrm{S}, \mathrm{H}$, 
$\mathrm{P}, \mathrm{H}^{-}, \mathrm{N}^{-}$) are conspicuous class of molecules accounting for about $25 \%$ of all the known interstellar and circumstellar molecular species. The incorporation of electric discharge right after the nozzle popularly known as pulsed discharge nozzle has been one of the most significant additions to the pulsed nozzle Fourier transform microwave (PNFTMW) spectrometer. This advancement has been instrumental for the successful measurement of the microwave spectra of these linear carbon chains, ions, transient species and radicals in the terrestrial laboratory. This has aided the successful astronomical observation of some of these linear carbon chain species. However, the fact that some of the experimental conditions; precise dilution factor, the right choices for the precursor and inert gases, parameters of the electrical discharge source cannot be specifically controlled has made the approach 'hit or miss' as one can only probe what is produced from the source but cannot specifically control what is produced (McCarthy et al., 1997, 1998; Thaddeus et al., 1998; Arunan et al., 2004). As a result, a number of species like the ions that are known not only to be present and detectable in ISM but also to be playing important role in the formation processes of other molecules in space cannot be detected because of the lack of accurate spectroscopic parameters. Theoretical prediction of spectroscopic parameters has been instrumental for the successful astronomical observation of a few molecular species such as $\mathrm{HNC}, \mathrm{HCO}^{+}, \mathrm{HOC}^{+}, \mathrm{N}_{2} \mathrm{H}^{+}, \mathrm{C}_{3} \mathrm{~N}, \mathrm{HCNH}^{+}$, $\mathrm{C}_{2} \mathrm{H}$, etc., (Buhl and Snyder, 1970; Zuckerman et al., 1972; Green et al., 1974; Tucker et al., 1974; Guélin et al., 1977; Woods et al., 1983; Ziurys et al., 1986; Kawaguchi et al., 1994) but the accuracy of theoretical predictions for some molecules cannot guide their successful astronomical detection. A recent study using a combined experimental and theoretical approach has been shown to be accurate in estimating rotational constants for the different linear carbon chains with the experimental accuracy of few $\mathrm{kHz}$ (Etim and Arunan, 2016a,b, 2017, Etim et al., 2016, 2017a, b, c).

Among the known interstellar and circumstellar molecules, isotopologues of $\mathrm{H}, \mathrm{C}, \mathrm{N}, \mathrm{O}$, and $\mathrm{S}$ containing species have also been detected. These isotopologues unlike their corresponding main carbon chain species do not suffer from opacity problems, thus, they are excellent tools for probing the physical and chemical conditions of ISM. The deuterated analogues are also used for testing ion-molecule processes for the formation and destruction of many H-containing molecular species in ISM (Wlodarczak, 1995; Markwick et al., 2005; Roueff et al., 2015). Focusing here on the isotopologues of the linear carbon chains, the starting point for their astronomical observation is the availability of accurate spectroscopic parameters. The experimental difficulty noted in the case of the main carbon chains is more pronounced for the isotopologues because of their low natural abundances. Theoretically, the methods that cannot accurately predict for the main carbon chains obviously cannot do so for their corresponding isotopologues. The combined experimental and theoretical approach depends on the availability of at least three experimental rotational constants but there is dearth of information regarding the experimental data for most of the linear carbon chain isotopologues. Thus, this approach cannot be utilized for estimating accurate rotational constants for the isotopologues. But could there be any correlation between the rotational constants of the linear carbon chains and their corresponding isotopologues which could be explored in estimating accurate rotational transitions for the isotopologues. Yes, there exist a correlation between the rotational constants of the linear carbon chains and their corresponding isotopologues which is being explored in this study.

Unidentified signal lines ('U' lines) are conspicuous components of almost every astronomical survey. These lines could come from diverse sources; new interstellar molecular species, isotopologues of known species or even weakly bound complexes which can survive under the conditions of the interstellar medium which are similar to the terrestrial laboratory conditions where they are probed. Assigning these ' $U$ ' lines begins with the availability of accurate rotational transitions. The present work aims at predicting accurate rotational constants within experimental accuracy for the different $\mathrm{C}, \mathrm{N}, \mathrm{O}, \mathrm{H}$, and $\mathrm{S}$ isotopologues of the $\mathrm{C}_{\mathrm{n}}, \mathrm{H}_{2} \mathrm{C}_{\mathrm{n}}$, $\mathrm{HC}_{\mathrm{n}} \mathrm{N}, \mathrm{HC}_{\mathrm{n}} \mathrm{O}, \mathrm{CH}_{3}(\mathrm{C} \equiv \mathrm{C})_{\mathrm{n}} \mathrm{H}, \mathrm{CH}_{3}(\mathrm{C} \equiv \mathrm{C})_{\mathrm{n}} \mathrm{CN}$, and $\mathrm{C}_{\mathrm{n}} \mathrm{X}(\mathrm{X}=\mathrm{N}$, $\mathrm{O}, \mathrm{Si}, \mathrm{S}, \mathrm{H}, \mathrm{P}, \mathrm{H}^{-}, \mathrm{N}^{-}$) carbon chains using the correlation between the rotational constants of the main carbon chains and their corresponding isotopologues. The predicted rotational constants could serve as excellent tools for detecting these molecules either via astronomical observation or through the numerous ' $\mathrm{U}$ ' lines. After a brief discussion on the methodology used in obtaining accurate rotational constants for the isotopologues, the obtained results based on the methodology will be discussed. A brief astrophysical implication of the results will be examined before the final conclusion.

\section{METHODOLOGY}

For the linear carbon chains and their isotopologues in this study, the rotational transitions needed for their astronomical observation are directly obtained from the rotational constant. Thus, with the availability of accurate rotational constants, the desired transitions of interest can be accurately determined. The ratio of the experimental $\left(B_{\text {exp }}\right)$ to the calculated $\left(\mathrm{B}_{\mathrm{cal}}\right)$ rotational constant for the main linear carbon chains is found to be approximately equal to that of the corresponding isotopologue (equation 1) within the experimental accuracy.

$\left(\mathrm{B}_{\text {exp }} / \mathrm{B}_{\text {cal }}\right)$ carbon chain $=\left(\mathrm{B}_{\exp } / \mathrm{B}_{\text {cal }}\right)$ isotopologue

This correlation is utilized in estimating accurate rotational constants for the different isotopologues of the carbon chains examined in this study. Experimental rotational constants $\left(\mathrm{B}_{\exp }\right)$ from experimental data and the combined experimental and theoretical approach have been reported (Etim and Arunan, 2016a,b). The calculated rotational constants for both the linear carbon chains and their corresponding isotopologues are obtained at the Hartree Fock method with the $6-311++\mathrm{G}^{* *}$ basis set. This level of theory is of course not expected to give accurate rotational constants. But since the same method is used for both the linear carbon chains and the corresponding isotopologues, there is cancellation of errors (Roothaan, 1951; Pople and Nesbet, 1954; Hariharan et al., 1973; Raghavachari et al., 1980). The polarization functions give additional flexibility to the description of molecular orbitals while the diffuse functions in the basis set 
allow the orbitals to occupy a larger region of space. Frequency calculations are carried out to ensure that only stable structures with no imaginary frequencies are considered. Gaussian 09 suite of programs is employed for all the quantum chemical calculations reported in this study (Frisch et al., 2009).

\section{RESULTS AND DISCUSSION}

The main $\mathrm{C}_{\mathrm{n}} \mathrm{H}$ chains have been probed experimentally up to the $\mathrm{C}_{14} \mathrm{H}$ with the use of Fourier transform microwave spectrometer with a pulsed discharge nozzle. Table 1 contains the calculated rotational constants for the $\mathrm{C}_{\mathrm{n}} \mathrm{H}$ isotopologues following the methodology described above. The error for the calculated rotational constants for the different isotopologues ranges from 0.065 to $0.150 \mathrm{MHz}$ for the deuterated analogues and 1.709 to 38.018 for the ${ }^{13} \mathrm{C}$ analogues. The calculated rotational constants are more accurate for the deuterated analogues as compared to the ${ }^{13} \mathrm{C}$ counterparts. This could be traced to the fact that in the $\mathrm{CnH}$ systems, there is only one $\mathrm{H}$ atom that can be replaced by the deuterated isotopologue while in the case of the ${ }^{13} \mathrm{C}$ isotopologue, though only one carbon atom is replaced by it isotope, but the effect is more pronounced in this case as compared to the deuterated isotopologue. The accuracy of the rotational constants obtained for the deuterated isotopologues are high enough and as such, they could be used for the astronomical searches of these molecular species. Also, this methodology could be used for predicting the rotational constants for other deuterated analogues of the $\mathrm{C}_{\mathrm{n}} \mathrm{H}$ carbon chains.

Table 1. Calculated rotational constants for $\mathrm{C}_{n} \mathrm{H}$ isotopologues

\begin{tabular}{|c|c|c|c|c|c|}
\hline System & $B_{\exp }$ & $\mathrm{B}_{\mathrm{cal}}$ & $\mathrm{B}_{\mathrm{exp}} / \mathrm{B}_{\mathrm{cal}}$ & *New B for iso & $\Delta \mathrm{B}(\mathrm{MHz})$ \\
\hline $\mathrm{C}_{3} \mathrm{H}$ & $11,186.3350$ & $11,147.120$ & 1.003518 & - & \\
\hline${ }^{13} \mathrm{CC}_{2} \mathrm{H}$ & $10,755.838$ & $10,806.887$ & 0.995276 & $10,844.90508$ & 38.0181 \\
\hline $\mathrm{C}_{5} \mathrm{H}$ & $2,395.1265$ & $2,377.265$ & 1.007513 & - & \\
\hline $\mathrm{C}_{5} \mathrm{D}$ & $2,262.128$ & $2,245.366$ & 1.007465 & $2,262.236481$ & 0.108488 \\
\hline${ }^{13} \mathrm{CC}_{4} \mathrm{H}$ & $2,319.3514$ & $2,310.512$ & 1.003825 & $2,327.871954$ & 8.520554 \\
\hline $\mathrm{C}_{7} \mathrm{H}$ & 875.484140 & 867.720 & 1.008948 & - & \\
\hline $\mathrm{C}_{7} \mathrm{D}$ & 841.76161 & 834.361 & 1.008870 & 841.8266521 & 0.065042 \\
\hline${ }^{13} \mathrm{CC}_{6} \mathrm{H}$ & 852.95949 & 847.089 & 1.006930 & 854.668539 & 1.709049 \\
\hline $\mathrm{C}_{6} \mathrm{H}$ & $1,391.18612$ & $1,378.179$ & 1.009438 & - & \\
\hline${ }_{13} \mathrm{CC}_{5} \mathrm{H}$ & $1,351.95593$ & $1,342.550$ & 1.00701 & $1,355.220857$ & 3.264927 \\
\hline $\mathrm{C}_{6} \mathrm{D}$ & $1,327.853$ & $1,315.587$ & 1.009323 & $1,328.003364$ & 0.150364 \\
\hline
\end{tabular}

It is known that the intensity of the rotational lines scales with the square of the dipole moments and the $\mathrm{C}_{\mathrm{n}} \mathrm{S}$ carbon chains are found to be highly polar with large dipole moments making them good candidates for both astronomical and laboratory detections. Astronomically, the $\mathrm{CS}, \mathrm{C}_{2} \mathrm{~S}, \mathrm{C}_{3} \mathrm{~S}$, and $\mathrm{C}_{5} \mathrm{~S}$ have all been observed in the interstellar medium. Table 2 display the calculated rotational constants for the $\mathrm{C}_{n} \mathrm{Si}$ isotopologues obtained following the methodology employed in this study.

Table 2. Calculated rotational constants for $\mathrm{C}_{\mathrm{n}} \mathrm{S}$ isotopologues

\begin{tabular}{|c|c|c|c|c|c|}
\hline System & $\mathrm{B}_{\exp }$ & $\mathrm{B}_{\mathrm{cal}}$ & $\mathrm{B}_{\mathrm{exp}} / \mathrm{B}_{\mathrm{cal}}$ & *New B for iso & $\Delta \mathrm{B}(\mathrm{MHz})$ \\
\hline $\mathrm{CS}$ & $24,495.5746$ & $25,212.700$ & 0.971557 & - & \\
\hline $\mathrm{C}^{33} \mathrm{~S}$ & $24,293.5746$ & $25,004.146$ & 0.971582 & $24,292.95251$ & 0.622094 \\
\hline $\mathrm{C}^{34} \mathrm{~S}$ & $24,103.5507$ & $24,808.430$ & 0.971587 & $24,102.80326$ & 0.747439 \\
\hline${ }^{13} C^{32} S$ & $23,123.808$ & $23,798.170$ & 0.971663 & $23,121.27811$ & 2.529891 \\
\hline $\mathrm{C}_{2} \mathrm{~S}$ & $6,477.74952$ & $6,586.906$ & 0.983428 & - & \\
\hline $\mathrm{C}_{2}{ }^{34} \mathrm{~S}$ & $6,335.8857$ & $6,442.564$ & 0.986546 & $6,335.799518$ & 0.086182 \\
\hline $\mathrm{C}_{3} \mathrm{~S}$ & $2,890.380$ & $2,942.826$ & 0.982178 & - & \\
\hline $\mathrm{C}_{3}{ }^{34} \mathrm{~S}$ & $2,820.36892$ & $2,871.461$ & 0.982207 & $2,820.286842$ & 0.082078 \\
\hline $\mathrm{C}_{5} \mathrm{~S}$ & 922.7033 & 939.167 & 0.982470 & - & \\
\hline $\mathrm{C}_{5}{ }^{34} \mathrm{~S}$ & 899.7161 & 915.759 & 0.982481 & 899.705645 & 0.010455 \\
\hline $\mathrm{C}_{6} \mathrm{~S}$ & 597.12449 & 606.712 & 0.984197 & - & \\
\hline $\mathrm{C}_{6}{ }^{34} \mathrm{~S}$ & 582.51 & 591.844 & 0.984229 & 582.49144 & 0.018560 \\
\hline $\mathrm{C}_{7} \mathrm{~S}$ & 414.42804 & 421.843 & 0.982422 & - & \\
\hline $\mathrm{C}_{7}{ }^{34} \mathrm{~S}$ & 404.54173 & 411.781 & 0.982420 & 404.542915 & 0.001185 \\
\hline
\end{tabular}

The error in the calculated rotational constants ranges from 0.001 to $2.529 \mathrm{MHz}$ for all the isotopologues considered. This high accuracy points to the possibility of using the results obtained from this approach for the astronomical searches of these isotopologues in which some of their main chains have been astronomically observed, examples $\mathrm{SiC}$ and $\mathrm{C}_{4} \mathrm{Si}$ (Etim and Arunan, 2016a,b, 2017, Etim et al., 2016, 2017a, b, c). 
The pure linear carbon chains $C_{n}$ are microwave inactive due to their lack of a permanent dipole moment as a result, they are only observed in the interstellar medium via their infrared transitions. The $\mathrm{C}_{n} \mathrm{Si}$ linear carbon chains are the isoelectronic analogues of the pure carbon chains. Unlike the pure carcon chains, the $\mathrm{C}_{\mathrm{n}} \mathrm{Si}$ chains are microwave active thus they can be observed both in the radio and infrared regions. The $\mathrm{C}_{\mathrm{n}} \mathrm{Si}$ chains are also known to have good dipole moments that are almost equal in Debye to the number of atoms in the chain. Table 3 shows the calculated rotational constants for the $\mathrm{C}_{\mathrm{n}} \mathrm{Si}$ isotopologues investigated in this study. The accuracy of the calculated rotational constants range from 0.005 to $0.109 \mathrm{MHz}$ for all the systems examined. This high level of accuracy strong supports the use of this approach for predicting rotational constants for these systems and related molecular species. Table 4 shows the calculated rotational constants for the $\mathrm{CH}_{3}(\mathrm{CC})_{n} \mathrm{H}$ isotopologues. The $\mathrm{CH}_{3}(\mathrm{CC})_{n} \mathrm{H}$ linear carbon chains are the methyl analogues of the $\mathrm{C}_{n} \mathrm{H}$ linear chains discussed above. Members of the $\mathrm{CH}_{3}(\mathrm{CC})_{n} \mathrm{H}$ chains have detected in interstellar medium.

Table 3. Calculated rotational constants for $\mathrm{SiC}_{\mathrm{n}}$ isotopologues

\begin{tabular}{cccccc}
\hline System & $\mathrm{B}_{\exp }$ & $\mathrm{B}_{\text {cal }}$ & $\mathrm{B}_{\exp } / \mathrm{B}_{\text {cal }}$ & $*$ New B for iso & $\Delta \mathrm{B}(\mathrm{MHz})$ \\
\hline $\mathrm{SiC}_{4}$ & $1,533.77206$ & $1,561.180$ & 0.982444 & - & \\
${ }^{29} \mathrm{SiC}_{4}$ & $1,510.2298$ & $1,537.211$ & 0.982448 & $1,510.223858$ & 0.005942 \\
${ }^{30} \mathrm{SiC}_{4}$ & $1,488.0256$ & $1,514.605$ & 0.982451 & $1,488.014727$ & 0.010873 \\
$\mathrm{Si}^{13} \mathrm{CC}_{3}$ & $1,532.0511$ & $1,559.540$ & 0.982374 & $1,532.160852$ & 0.109752 \\
& & & & - & \\
$\mathrm{SiC}_{6}$ & 611.25102 & 621.937 & 0.982818 & & \\
${ }^{29} \mathrm{SiC}_{6}$ & 602.2978 & 612.831 & 0.982812 & 602.301477 & 0.003677 \\
$\mathrm{Si}^{13} \mathrm{CC}_{5}$ & 608.7851 & 619.450 & 0.982783 & 608.806751 & 0.021651 \\
${ }^{30} \mathrm{SiC}_{6}$ & 593.7901 & 604.177 & 0.982808 & 593.796168 & 0.006068 \\
\hline
\end{tabular}

$*=\mathrm{B}_{\exp }$ isotopologue $=\left(\mathrm{B}_{\exp }\right.$ carbon chain $* \mathrm{~B}_{\text {cal }}$ isotopologue $) / \mathrm{B}_{\text {cal }}$ carbon chain

Table 4. Calculated rotational constants for $\mathrm{CH}_{3} \mathrm{C}_{n} \mathrm{H}$ isotopologues

\begin{tabular}{cccccc}
\hline System & $\mathrm{B}_{\exp }$ & $\mathrm{B}_{\text {cal }}$ & $\mathrm{B}_{\exp } / \mathrm{B}_{\text {cal }}$ & $*$ New B for iso & $\Delta \mathrm{B}(\mathrm{MHz})$ \\
\hline $\mathrm{CH}_{3} \mathrm{CCH}$ & $8,545.84$ & $8,648.27$ & 0.988156 & - & \\
${ }^{13} \mathrm{CH}_{3} \mathrm{CCH}$ & $8,313.23$ & $8,410.48$ & 0.988437 & 8310.866382 & 2.363618 \\
$\mathrm{CH}_{3} \mathrm{CCD}$ & $7,788.14$ & $7,881.17$ & 0.988196 & $7,787.825523$ & 0.314477 \\
\hline
\end{tabular}

$*=\mathrm{B}_{\exp }$ isotopologue $=\left(\mathrm{B}_{\exp }\right.$ carbon chain $* \mathrm{~B}_{\text {cal }}$ isotopologue $) / \mathrm{B}_{\text {cal }}$ carbon chain

Methylcyanopolyynes, $\mathrm{CH}_{3}(\mathrm{C} \equiv \mathrm{C})_{\mathrm{n}} \mathrm{CN}$ are the methyl analogues of the cyanopolyynes with alternating single and triple bond terminated by a methyl group at one end and cyano group at the other end. The first three members;
$\mathrm{CH}_{3} \mathrm{CN}, \mathrm{CH}_{3} \mathrm{C}_{3} \mathrm{~N}$ and $\mathrm{CH}_{3} \mathrm{C}_{5} \mathrm{~N}$ of the methylcyanopolyynes have been detected in interstellar space. Table 5 shows the calculated rotational constants for the isotopologues of this chain considered in this study.

Table 5. Calculated rotational constants for $\mathrm{CH}_{3} \mathrm{C}_{\mathrm{n}} \mathrm{N}$ isotopologues

\begin{tabular}{cccccc}
\hline System & $\mathrm{B}_{\exp }$ & $\mathrm{B}_{\text {cal }}$ & $\mathrm{B}_{\text {exp }} / \mathrm{B}_{\text {cal }}$ & $*$ New B for iso & $\Delta \mathrm{B}(\mathrm{MHz})$ \\
\hline $\mathrm{CH}_{3} \mathrm{CN}$ & $9,198.899299$ & $9,355.67$ & 0.983243 & - & \\
${ }^{13} \mathrm{CH}_{3} \mathrm{CN}$ & $8,933.3139$ & $9,082.74$ & 0.983548 & 8930.542721 & 2.771179 \\
$\mathrm{CH}_{3} \mathrm{C}^{15} \mathrm{~N}$ & $8,922.04343$ & $9,076.13$ & 0.983023 & 8924.043483 & 2.0001 \\
\hline
\end{tabular}

Though no member of the $\mathrm{HC}_{\mathrm{n}} \mathrm{S}$ chains has been astronomically observed, the high abundance of molecular hydrogen in space and the prevalence of S-bearing molecules in different astronomical sources put the hydrogenated molecular species of the form $\mathrm{HC}_{\mathrm{n}} \mathrm{S}$ and their isotopologues as important candidates for astronomical detection. In Table 6 , the calculated rotational constants for the $\mathrm{HC}_{\mathrm{n}} \mathrm{S}$ systems are shown. The accuracy of 0.3332 to $2.4573 \mathrm{MHz}$ is in good order with respect to the astronomical searches of these species. In Table 7, the calculated rotational constants for the different isotopologues of the $\mathrm{HC}_{\mathrm{n}} \mathrm{N}$ systems are shown. The accuracy for the calculated systems are in good agreement with the range expected to be useful in guiding successful astronomical searches. This further supports the fact that the approach employed in this study could be used in predicting rotational constants for different carbon chain isotopologues of astrophysical interest.

Table 6. Calculated rotational constants for $\mathrm{HC}_{\mathrm{n}} \mathrm{S}$ isotopologues

\begin{tabular}{cccccc}
\hline System & $\mathrm{B}_{\exp }$ & $\mathrm{B}_{\text {cal }}$ & $\mathrm{B}_{\exp } / \mathrm{B}_{\text {cal }}$ & $*$ New B for iso & $\Delta \mathrm{B}(\mathrm{MHz})$ \\
\hline $\mathrm{HC}_{3} \mathrm{~S}$ & $2,688.4362$ & $2,628.746$ & 1.022707 & - & \\
$\mathrm{HC}_{3}{ }^{34} \mathrm{~S}$ & $2,623.1147$ & $2,564.549$ & 1.022837 & 2622.781497 & 0.333203 \\
$\mathrm{DC} 3 \mathrm{~S}$ & $2,520.6047$ & $2,462.238$ & 1.023705 & 2518.147349 & 2.457351 \\
\hline$*=\mathrm{B}_{\text {exp }}$ isotopologue & $=\left(\mathrm{B}_{\text {exp }}\right.$ carbon chain $* \mathrm{~B}_{\text {cal }}$ isotopologue $) / \mathrm{B}_{\text {cal }}$ carbon chain & &
\end{tabular}


Table 7: Calculated rotational constants for $\mathrm{HC}_{\mathrm{n}} \mathrm{N}$ isotopologues

\begin{tabular}{|c|c|c|c|c|c|}
\hline System & $\mathrm{B}_{\exp }$ & $\mathrm{B}_{\mathrm{cal}}$ & $\mathrm{B}_{\exp } / \mathrm{B}_{\mathrm{cal}}$ & *New B for iso & $\Delta \mathrm{B}(\mathrm{MHz})$ \\
\hline $\mathrm{HCN}$ & $44,315.97$ & $46,364.002$ & 0.955827 & - & \\
\hline $\mathrm{DCN}$ & $36,207.50$ & $37,731.875$ & 0.959600 & $36,065.149$ & 142.350996 \\
\hline $\mathrm{HC}_{3} \mathrm{~N}$ & $4,459.058$ & $4,633.475$ & 0.962357 & - & \\
\hline $\mathrm{DC}_{3} \mathrm{~N}$ & $4,221.580858$ & $4,298.619$ & 0.982078 & 4136.806919 & 84.773938 \\
\hline $\mathrm{HC}_{5} \mathrm{~N}$ & $1,331.3313$ & $1,347.875$ & 0.987726 & - & \\
\hline $\mathrm{DC}_{5} \mathrm{~N}$ & $1,271.057$ & $1,286.793$ & 0.987771 & 1270.9990 & 0.057985 \\
\hline $\mathrm{HC}_{7} \mathrm{~N}$ & 564.00112 & 569.550 & 0.990257 & - & \\
\hline $\mathrm{DC}_{7} \mathrm{~N}$ & 545.3153 & 550.682 & 0.990254 & 545.316943 & 0.001643 \\
\hline $\mathrm{H}^{13} \mathrm{CC}_{6} \mathrm{~N}$ & 551.64401 & 562.968 & 0.979885 & 557.483246 & 5.839235 \\
\hline $\mathrm{HC}_{7}{ }^{15} \mathrm{~N}$ & 552.25338 & 557.740 & 0.990163 & 552.306180 & 0.05280 \\
\hline $\mathrm{HC}_{9} \mathrm{~N}$ & 290.518322 & 292.958 & 0.991672 & - & \\
\hline $\mathrm{DC}_{9} \mathrm{~N}$ & 282.91852 & 285.299 & 0.991656 & 282.9231042 & 0.004584 \\
\hline $\mathrm{H}^{13} \mathrm{CC}_{8} \mathrm{~N}$ & 285.2948 & 289.563 & 0.985260 & 287.151595 & 1.856795 \\
\hline $\mathrm{HC}_{9}{ }^{15} \mathrm{~N}$ & 285.05909 & 287.712 & 0.990780 & 285.316009 & 0.256919 \\
\hline $\mathrm{HC}_{11} \mathrm{~N}$ & 169.06295 & 170.329 & 0.992567 & - & \\
\hline $\mathrm{DC}_{11} \mathrm{~N}$ & 165.4069 & 166.649 & 0.992547 & 165.410303 & 0.003403 \\
\hline $\mathrm{HC}_{11}{ }^{15} \mathrm{~N}$ & 166.39526 & 167.651 & 0.992510 & 166.404855 & 0.009595 \\
\hline $\mathrm{H}^{13} \mathrm{CC}_{10} \mathrm{~N}$ & 166.28861 & 168.435 & 0.987257 & 167.183028 & 0.894418 \\
\hline $\mathrm{HC}_{13} \mathrm{~N}$ & 106.97258 & 107.706 & 0.993190 & - & - \\
\hline $\mathrm{DC}_{13} \mathrm{~N}$ & 104.994997 & 105.722 & 0.993123 & 105.00209 & 0.007093 \\
\hline $\mathrm{HC}_{15} \mathrm{~N}$ & 71.950133 & 72.408 & 0.993676 & - & \\
\hline $\mathrm{DC}_{15} \mathrm{~N}$ & 70.791053 & 71.246 & 0.993614 & 70.795481 & 0.004428 \\
\hline $\mathrm{HC}_{17} \mathrm{~N}$ & 50.70323 & 51.009 & 0.994005 & - & \\
\hline $\mathrm{DC}_{17} \mathrm{~N}$ & 49.978955 & 50.283 & 0.993953 & 49.981582 & 0.002627 \\
\hline $\mathrm{HC}_{19} \mathrm{~N}$ & 37.063306 & 37.282 & 0.994107 & - & - \\
\hline $\mathrm{DC}_{19} \mathrm{~N}$ & 36.59256 & 36.805 & 0.994228 & 36.589104 & 0.003456 \\
\hline
\end{tabular}

$*=\mathrm{B}_{\exp }$ isotopologue $=\left(\mathrm{B}_{\exp }\right.$ carbon chain $* \mathrm{~B}_{\mathrm{cal}}$ isotopologue $) / \mathrm{B}_{\mathrm{cal}}$ carbon chain

\section{Astrophysical Implications:}

The possibility that most of the 'U' lines associated with the known linear interstellar carbon chains belong to their isotopologues cannot be totally ruled out. With the availability of accurate rotational constants, some of the 'U' lines could be assigned.

\section{CONCLUSION}

Accurate rotational transitions which are indispensable tools for any successful astronomical observation of molecular species have been estimated for the $\mathrm{D},{ }^{13} \mathrm{C},{ }^{17} \mathrm{O},{ }^{18} \mathrm{O},{ }^{33} \mathrm{~S}$ and ${ }^{34} \mathrm{~S}$ isotopologues of the $\mathrm{C}_{n}, \mathrm{H}_{2} \mathrm{C}_{\mathrm{n}}, \mathrm{HC}_{\mathrm{n}} \mathrm{N}, \mathrm{HC}_{\mathrm{n}} \mathrm{O}$, $\mathrm{CH}_{3}(\mathrm{C} \equiv \mathrm{C})_{\mathrm{n}} \mathrm{H}, \mathrm{CH}_{3}(\mathrm{C} \equiv \mathrm{C}){ }_{\mathrm{n}} \mathrm{CN}$, and $\mathrm{C}_{\mathrm{n}} \mathrm{X} \quad(\mathrm{X}=\mathrm{N}, \mathrm{O}, \mathrm{Si}, \mathrm{S}, \mathrm{H}$, $\left.\mathrm{P}, \mathrm{H}^{-}, \mathrm{N}^{-}\right)$linear carbon chains which are the dominant theme in interstellar chemistry. The predicted rotational constants 
obtained using the correlation between the rotational constants of the linear carbon chains and their corresponding isotopologues are within experimental accuracy of few $\mathrm{KHz}$ for systems with known experimental constants and the same high level of accuracy is expected for systems with no experimental rotational constants. These accurate rotational constants can guide successful astronomical observation of these isotopologues which are also good probes of the physical and chemical conditions of the interstellar medium. They could also be utilized in reducing the ' $U$ ' lines associated with the main carbon chains of which the possibility of the ' $U$ ' lines corresponding to the isotopologues of the main carbon chains cannot be totally ruled out.

\section{ACKNOWLEDGEMENTS}

EEE acknowledges a research fellowship from the Indian Institute of Science, Bangalore.

\section{REFERENCES}

Arunan, E., Dev, S. and Mandal, P. K. (2004). Pulsed nozzle fourier transform microwave spectrometer: advances and applications. Applied Spectroscopy Reviews, 39(2): 131-181. https://doi.org/10.1081/ASR-120030906

Buhl, D. and Snyder, L. E. (1970). Unidentified Interstellar Microwave Line. Nature, 228:267. https://doi.org/10.1038/228267a0

Etim, E. E., and Arunan, E. (2015). Rotational Spectroscopy and Interstellar Molecules. Planex, 5:16-21.

Etim, E. E., Gorai, P., Das, A. and Arunan, E. (2017). Interstellar Protonated Molecular Species. Advances in Space Research, 60: 709-721. https://doi.org/10.1016/j.asr.2017.04.003

Etim, E. E., Arunan, E. (2017). C5H9N Isomers: Pointers to Possible Branched Chain Interstellar Molecules. Advances in Space Research, 59(4): 1161-1171. https://doi.org/10.1016/j.asr.2016.11.021

Etim, E. E., Gorai, P., Das, A., Chakrabati, S. K., Arunan, E. (2016). C5H9N Isomers: Pointers to Possible Branched Chain Interstellar Molecules. The Astrophysical Journal, 832: 144. https://doi.org/10.3847/0004-637X/832/2/144

Etim, E. E and Arunan, E. (2016). Interstellar isomeric species: Energy, stability and abundance relationship. EPJ-P., 131: 448. https://doi.org/10.1140/epjp/i2016-16448-0

Frisch, M. J., Trucks, G. W., Schlegel, H. B., Scuseria, G. E., Robb, M. A., Cheeseman, J. R., et al., (2009). Expanding the limits of computational chemistry. Gaussian 09, revision D.01. Gaussian, Inc., Wallingford, CT

Green, S., Montgomery, Jr J. A. and Thaddeus, P. (1974). Tentative Identification of U93.174 as the Molecular Ion N2H+. The Astrophysical Journal, 193: L89-L91. https://doi.org/10.1086/181639

Guélin, M. and Thaddeus, P. (1977). Tentative Detection of the C3N Radical. The Astrophysical Journal, 212: L81-L85. https://doi.org/10.1086/182380

Hariharan, P.C. and Pople, J. A. (1973). The Influence of polarization functions on molecular orbital energies hydrogenation. Theor.
Chim. Acta., 28: 213- 222

https://doi.org/10.1007/BF00533485

Kawaguchi, K., Kasai, Y., Ishikawa, S. I., Ohishi, M. Kaifu, N. and Amano, T. (1994). Detection of a New Molecular Ion HC3NH+ in TMC-1. The Astrophysical Journal, 420: L95-L97. https://doi.org/10.1086/187171

Markwick, A. J., Charnley, S, B., Butner, H. M., and Millar, T. J. (2005) Interstellar CH3CCD. The Astrophysical Journal, 627: L117. https://doi.org/10.1086/432415

McCarthy, M. C., Travers, M J., KovaCs, A., Gottlieb,C. A. and Thaddeus, P. (1997). Eight New Carbon Chain Molecules. The Astrophysical Journal Supplement Series, 113: 105-120. https://doi.org/10.1086/313050

McCarthy, M. C., Grabow, J. -U., Travers,M. J., Chen,W., Gottlieb, C. A. and Thaddeus, P. (1998). Laboratory Detection of the carbon chains HC15N and HC17N. The Astrophysical Journal, 494 L231-L234. https://doi.org/10.1086/311188

Pople, J. A., and Nesbet, R. K. (1954). Self-Consistent Orbitals for Radicals. J. Chem. Phys., 22: 571-72. https://doi.org/10.1063/1.1740120

Raghavachari, K., Binkley, J. S., Seeger, R., and Pople, J. A. (1980). Selfconsistent molecular orbital methods. XX. A basis set for correlated wave functions. J. Chem. Phys., 72: 650. https://doi.org/10.1063/1.438955

Roothaan, C. C. J. (1951). New Developments in Molecular Orbital Theory. Rev. Mod. Phys., 23(2): 69-89. https://doi.org/10.1103/RevModPhys.23.69

Roueff, E., Loison, J. C. and Hickson, K. M. (2015). Isotopic fractionation of carbon, deuterium, and nitrogen: A full chemical study. A\&A., 576: A99.

Thaddeus, P., McCarthy, M. C., Travers, M. J., Gottlieb, C. A. and Chen, W. (1998). New carbon chains in the laboratory and in interstellar space. Faraday Discussion, 109: 121-135. https://doi.org/10.1039/a800286j

Tucker, K. D., Kutner, M. L. and Thaddeus, P. (1974). The Ethynyl Radical C2H - A New Interstellar Molecule. The Astrophysical Journal, 193: L115-L119. https://doi.org/10.1086/181646

Wlodarczak, G. (1995). Rotational Spectroscopy and Astrochemistry. J. of Molecular Structure, 347: 131-142. https://doi.org/10.1016/0022-2860(95)08541-3

Woods, R. C., Gudeman, C. S., Dickman, R. L., Goldsmith, P. F., Huguenin, G. R., et al., (1983). The HCO+/HOC+ abundance ratio in molecular clouds. The Astrophysical Journal, 270: 583588. https://doi.org/10.1086/161150

Ziurys, L. M. and Turner, B. E. (1986). HCNH+: A New Interstellar Molecular Ion. The Astrophysical Journal, 302: L31-L36. https://doi.org/10.1086/184631

Zuckerman, B., Morris, M., Palmer, P. and Turner, B. E. (1972) Observations of CS, HCN, U89.2, and U90.7 in NGC 2264. The Astrophysical Journal, 173: L125. https://doi.org/10.1086/18093

\section{How to cite this article}

Etim, E.E., Mbakara, I.E., Inyang, E.J., Ushie, O.A., Lawal, U. and Andrew, C. (2017). Spectroscopy of Linear Interstellar Carbon Chain Isotopologues: Meeting Experimental Accuracy. Tropical Journal of Applied Natural Sciences, 2(2): 11-16.

Doi: https://doi.org/10.25240/TJANS.2017.2.1.03. 